\title{
Performance assessment of static and dynamic routings using 6LoWPAN on small scenarios applied to monitoring of Barranquilla flash flood
}

\section{Piñeres -Espitia Gabriel}

Universidad de la Costa: Corporacion Universitaria de la Costa

shariq aziz butt ( $\nabla$ shariq2315@gmail.com )

Superior university

\section{Estévez -Ortiz Francisco}

University of Granada: Universidad de Granada

Cama -Pinto Alejandro

Universidad de la Costa: Corporacion Universitaria de la Costa

\section{Research}

Keywords: 6LoWPAN, Wireless Sensor Networks (WSN), Routing protocol, Low-Power Listening (LPL), Network monitoring and measurements, flash flood

Posted Date: April 9th, 2021

DOI: https://doi.org/10.21203/rs.3.rs-304521/v1

License: (9) This work is licensed under a Creative Commons Attribution 4.0 International License. Read Full License 


\section{Abstract}

The Internet of Things (IoT) is growing rapidly due to the wireless network that provides connectivity to devices at anytime and anywhere. Currently, the wireless sensor network is involved in many research fields like smart health monitoring, smart cities, and smart industries. From all of these, flood monitoring is the most important field in the loT wireless network to alert about the occurrence of any abnormalities. To monitor the environment wireless sensor network needs a decision-making protocol that sense and route the information timely. The present work includes numerous use of Low Power Wireless Personal Area Networks (6LoWPAN) with IPv6 protocol defined by the Internet Engineering Task Force (IETF) due to its different test conditions, analysing static and dynamic routing and its impact on different performance metrics such as latency and packet losses for their application in monitoring system of the flash floods in any region. In this study, we are using IPv6 6LoWPAN to develop a wireless warning system before a flood event in "The Brigade" in Barranquilla city. The basic purpose for making system is to secure the city from costly damage and life loss. Different types of traffic and different 1-/2-hops scenarios have been considered. In order to implement our system, we use the well-known TelosB platform jointly with TinyOS, BLIP 2.0 and LPL. The experiment result shows that time on $512 \mathrm{~ms}$ and 1024 ms with a packet of $120 \mathrm{~B}$ obtain good performance on the metrics used for the tests.

\section{Introduction}

The Internet of Things (IoT) is growing due to wireless sensor network that provide smart devices connectivity from anywhere and is evolving many research fields like smart hospitals, smart traffic, smart city, environment monitoring and smart decision making systems. This wireless connectivity also increases the data traffic in loT $[1,2,3]$. To transmit the data the network needs some new platform, technologies, network architectures and network protocols to route the data $[4,5,6]$. The wireless network has many protocols, one of these protocols is the IPv6 for Low Power Wireless Personal Area Networks (6LoWPAN), defined by the Internet Engineering Task Force (IETF) in the RFC4944 [7]. It is very vastly in use IPv6 protocol over IEEE 802.15.4 [8] due to its compatibility with wireless sensor nodes [7-9]. In IoT the research community has developed many environment monitoring applications like Early Warning Systems (EWS) for catastrophic events to improve the life quality and lifesaving $[10,12,13]$. In the case of the EWS, a monitoring system that is the objective of this work for the flash floods that occur in the rainy season in the city of Barranquilla - Colombia. This problem has occurred for many years in this city, therefor this work support by the University of the Coast at a zone known as "The Brigade" for generate alerts when this event is occurred $[11,14]$. The existing studies include damages of floods in terms of cost and life. We do not find any study and EWS system for Barranquilla - Colombia to alert from flood. We develop a system and mitigate different kinds of tests with three nodes to send packets, using the 6LoWPAN logical addressing method and two routing protocols. This allow analysing the implementation of 6LoWPAN in the monitoring of flash floods in the area of "The Brigade" as shown in Fig. 1a section of the interest zone where the flash flood occurs. 
In this context, the study of the performance of 6LoWPAN considering different routing methods, static and dynamic. In order to compare the performance, the present work is based on the TelosB platform [15], including TinyOS as embedded operative system and the Berkeley Low-Power IP stack (BLIP) [16] as 6LoWPAN network stack. Additional libraries for dynamic IPv6 routing like, IPv6 Routing Protocol for LowPower and Lossy Networks (RPL) [17] and for energy saving purposes like, Low-Power Listening (LPL) [18] have been used. The results are more important in this work therefore the methodologies for the evaluation of 6LoWPAN performance with the established metrics, obtaining impacts important for the select routing type and the channel scan time for the energy saving with the LPL protocol. Furthermore, is possible to analysing the network performance according the select packet length. Criteria is also provided for the selection of TelosB platform and 6LoWPAN applied a monitoring network for flash floods in the "The Brigade" area of the city of Barranquilla. The rest of the paper is organized as follows: Sect. 2 provides an overview of the most relevant work about 6LoWPAN applications and metrics for WSN.

Section 3 describes the materials and methods, as well as the test scenarios used. Section 4 presents the results and its analysis. Finally, Sect. 5 describes the most relevant conclusions of this paper.

\section{6lowpan: Applications And Metrics For Wsn}

\subsection{Emerging technologies for Early Warning System}

The natural hazards affect large part of the population, resulting in severe economic and human losses. For mitigate the impact in the population of the natural hazards are implemented Early Warning System (EWS) in vulnerable areas. This System are an important tool to hazard risk management and many applications requires this solutions to face phenomenon such as tornadoes [19,20], floods [21, 22], landslides [23, 24], flash-floods [25, 26], tsunamis [27], and similar. Therefore, the use of emerging technologies in EWS is relevance and is a challenge for the researchers. This technologies consist of innovations such as loT, new protocols and low cost platforms, which have been implemented in solutions for monitoring system and loT. For example, in Surabaya - Indonesia have development an loT system in EWS to garbage collector robots and be able to monitoring severe and dangerous conditions; this prototype can monitoring the battery level information and operation to the robot; the ESP8266-12 module allows the WIFI communication with an android platform [28]. In Malaysia an loT system is proposed for a flood EWS; this system consist of a wireless sensor networks, wind sensors and cellphone images that are sent to cloud using Zigbee and $3 G$ for monitoring and warning to the users [29].In Pakistan, a low cost flood EWS is development using Raspberry Pi platform, video camera, temperature and humidity sensors, energy system (battery and solar panels); this system send GSM data to Web dashboard, showing the level water [30]. In Italy, a WSN (Wireless Sensor Networks) is used to estimate landslide; for this, the RF signal is analyzed in the nodes of the WSN and establish its location in draw a grid map; the change in the locate to the node can indicate that a landslide is present by soil movement [31]. For this work, the flash flood are the principal context, because have caused material and human losses in recent decades in the Barranquilla city, also causing congestion of traffic and dragging 
sediments by the flow. There are thirty zones where flash floods occur due to the absence of sewerage over the city, and although some canalizations work has been carried out in some cases, it is important to have systems based on emerging technologies that can generate warning for the vulnerable population. This motivated different studies from the "Universidad de la Costa" to generate solutions to this problem in Barranquilla [32, 33, 34].

\subsection{LoWPAN and applications}

The use of emerging technologies for environment applications is important for evaluate its possible application in EWS. These studies can be complemented by the analysis of IPv6 applications for constrained environments such as the technique 6LoWPAN, in order working on top of the IEEE 802.15.4standard (see Fig. 2). Between the set of wireless protocols [35], 6LoWPAN shows a major increase of use in several fields like the web or military applications $[36,37]$ or even as preferred communication method for embedded operative systems such as TinyOS or ContikiOS [38].

As a trend, there are a lot of different studies about its performance like the one about high-precision agriculture [39] or the latency and energy consumption related to networking mobility (NEMO) [40], or even studies about network congestion problems

[41], security in point-to-point networks [42], impact in medical applications within high-mobility environments $[43,44]$ or deep analysis of the energy consumption among the nodes $[45,46]$.

In the analysis of the literature different performance metrics was analyzed. Additionally the factors that produced incidence in the metrics were identified. Furthermore, the hardware and software platforms used for 6LoWPAN were analysed. Based on the above, some researches focused on high-precision agriculture have been developed using the TelosB platform with different sensors jointly with TinyOS, RPL-6LoWPAN and LPL. In this work different time intervals (512, 1024 and $2048 \mathrm{~ms})$ and their impact in the battery lifetime have been analysed, resulting in an improvement of the lifetime through using a 2048 ms interval [47]. Other relevant work is focused on the carbon-cycle measuring in the Peruvian Amazon jungle, using the same platform [48]. Other applications use the same platform, testing instead of TinyOS, ContikiOS [49]. This revision is important for select the TelosB platform how a tool for the tests analysis in this work. Likewise for the time selection in the tests with the LPL protocol.

Different works have analysed the performance of different platforms, covering a wide spectrum among the use of various microcontrollers like Waspmote, TelosB, Arduino and radios like XBee, MicaZ and iMote2. These works also analysed different metrics and parameters, such as the delay in the message reception or the throughput using different payloads [50]. Researches in the field of second layer protocols [51] have analysed different metrics such as the duty cycle, latency and throughput, looking for the optimal use conditions in ContikiOS [52].

The above analysis is important for the selection of the metrics, such as the latency and the packet loss. Similarly this analysis allows define the platform TelosB y the framework TinyOS for the use in the traffics tests for the proposed scenario. On the other hand, RPL, as a part of 6 LOWPAN, is being widely 
studied [53], not only in the field of Wireless Personal Area Networks (WPANs), but also in the field of Body Area Networks (BANs) [54,55]. Thus the comparative between RPL and static routing is an important factor for the analysis in the tests.

In this study, we are using IPv6 6LoWPAN to develop a wireless warning system before a flood event in "The Brigade" in Barranquilla city. The basic purpose for making system is to secure the city from costly damage and life loss. Different types of traffic and different 1-/2-hops scenarios have been considered. In order to implement our system, we use the well-known TelosB platform jointly with TinyOS, BLIP 2.0 and LPL. The experiment result shows that time on $512 \mathrm{~ms}$ and $1024 \mathrm{~ms}$ with a packet of $120 \mathrm{~B}$ obtain good performance on the metrics used for the tests.

\section{Mitigation Of System}

\subsection{Materials and methods}

This section presents the scenarios and tests carried out. The present work is based on the Telos $B$ platform, which is a low-cost and well-known platform in the academic world. This platform also offers support to the IEEE 802.15.4 and 6LOWPAN through the use of TinyOS, BLIP, RPL and LPL. In order to capture and analyse traffic, like the Internet Control Message Protocol version 6 (ICMPV6), Wireshark [54, 56] has been used. The traffic for these tests is ICMPv6 (Internet Control Message Protocol for the Internet

Protocol Version 6) packet, which has been generated using the tool PINGv6. As a result, Round Trip Times (RTT) of the nodes is received on the sink, measuring packet losses and packet delays for the performance analysis. The Fig. 3 show a flowchart for the implementation of 6LoWPAN on the TelosB platform and the basics tests for the initially connectivity.

\subsection{Scenarios}

The scenario presented in this paper is based on three nodes and a host computer. The topology is pointto-point and involves a node working as sink and two as sensor nodes. The Fig. 4 shows the proposed scenario, where the node 1 jointly with the computer acts as sink and the node 2 acts as router.

This work considers the Line-Of-Sight (LOS) between nodes as a reference in order to deploy the nodes. Thus, the network has been designed avoiding the LOS between node 1 and 3 in order to generate a directed routing scheme (i.e. the 2-hops route used in the tests). For this network, both static and dynamic routing methods have been considered. Table 1 shows the static routing configuration, for the dynamic routing, RPL is the protocol used. 
Table 1

IPV6 addressing for 6LoWPAN Network

\begin{tabular}{|c|c|c|}
\hline Node & IPv6 Address & Location \\
\hline \multirow[t]{2}{*}{1} & \multirow[t]{2}{*}{ FEC0::1 } & $10^{\circ} 59^{\prime} 41.10^{\prime \prime} \mathrm{N} ; 74^{\circ} 47^{\prime} 27.82^{\prime \prime} \mathrm{O}$ \\
\hline & & University of the Coast \\
\hline 2 & FEC0::7 & $10^{\circ} 59^{\prime} 42.94^{\prime \prime N} ; 74^{\circ} 47^{\prime} 29.11 " \mathrm{O}$ \\
\hline 3 & FECO::8 & $10^{\circ} 59^{\prime} 40.61 " \mathrm{~N} ; 74^{\circ} 47^{\prime} 31.41^{\prime \prime O}$ \\
\hline \multirow[t]{2}{*}{ Computer / Edge Router } & \multirow[t]{2}{*}{ FEC0::100 } & $10^{\circ} 59^{\prime} 41.10^{\prime \prime} \mathrm{N} ; 74^{\circ} 47^{\prime} 27.82^{\prime \prime} \mathrm{O}$ \\
\hline & & University of the Coast \\
\hline
\end{tabular}

\subsection{Test Description}

The tests carried out have been based on the sending of PINGV6 messages, first, to test the connectivity among nodes, afterwards, generating traffic during 5 minutes that can be captured and analysed with Wireshark. The performance of the network is based on the packet size and the distance between nodes. Table 2 shows all the different tests carried out.

Table 2

Performance tests for 1- and 2-hops 6LoWPAN networks

\begin{tabular}{|c|c|c|c|c|c|}
\hline $\begin{array}{l}\text { Distance to sink } \\
\text { (m) }\end{array}$ & Hops & Nodes & $\begin{array}{l}\text { Packet size } \\
\text { (Bytes) }\end{array}$ & $\begin{array}{l}\text { Time Sleep Interval } \\
\text { (ms) }\end{array}$ & $\begin{array}{l}\text { Routing } \\
\text { type }\end{array}$ \\
\hline 10 & 1 & $\begin{array}{l}\text { Node } 1 \text { - } \\
\text { Node } 2\end{array}$ & 120,1133 & 0,1024 & Static \\
\hline 20 & 1 & $\begin{array}{l}\text { Node } 1 \text { - } \\
\text { Node } 2\end{array}$ & 120,1133 & 0,1024 & Static \\
\hline 30 & 1 & $\begin{array}{l}\text { Node } 1 \text { - } \\
\text { Node } 2\end{array}$ & 120,1133 & 0,1024 & Static \\
\hline 40 & 1 & $\begin{array}{l}\text { Node } 1 \text { - } \\
\text { Node } 2\end{array}$ & 120,1133 & 0,1024 & Static \\
\hline 65 & 1 & $\begin{array}{l}\text { Node } 1 \text { - } \\
\text { Node } 2\end{array}$ & 120,1133 & $0,512,1024$ & $\begin{array}{l}\text { Static, } \\
\text { RPL }\end{array}$ \\
\hline 165 & 2 & $\begin{array}{l}\text { Node } 1 \text { - } \\
\text { Node } 3\end{array}$ & 120,1133 & $0,512,1024$ & $\begin{array}{l}\text { Static, } \\
\text { RPL }\end{array}$ \\
\hline
\end{tabular}

The metrics analysed in the present work are shown below and are based on previous works $[56,57,60]$, considering those, which generate delays in the network and changes in the packet delivery rate.

- Packet losses

- RTT Average time

- RTT Average delay 
- Sending packet delay

- Average Jitter

\subsubsection{Packet Losses}

The packet losses have been measured firstly between the sink and the node 2, with only one hop, varying the payload, the time interval configuration of LPL and the distance between both nodes. After this test, a second analysis has been carried using all the nodes in the network and analysing the performance with two hops, varying also the time configuration of LPL and the routing type. The traffic monitoring has been focused on nodes 2 and 3 .

\subsubsection{RTT average time}

To calculate this metric, the time between packet sending and packet response arrival has been measured. A previous theoretic analysis shows that the packets could suffer of delays, due to the processing time, which is associated to routing tasks among the network. It can be affected also by delays derived of the application of LPL. The RTT average time is measured as the sum of the RTT average time for a 5 minutes test, using the same tests and conditions than in the packet losses analysis.

\subsubsection{RTT sending average delay}

The RTT sending delay is measured as the elapsed time between sending two packets with acknowledging receive, consecutively. This metric is calculated because in some cases the packets sent from the sink do not produce any reply from the nodes. Then, the RTT sending average delay is the average time elapsed between sending two packets with acknowledging receive consecutively, using the same factors and conditions as in the packet losses analysis.

The RTT delay is measured in the sink by the information received in the Wireshark tool $[58,59]$.

\subsubsection{Sending packet average delay}

The packet sending response has been analysed, regardless of the successful acknowledge message reception, as the elapsed time between the sending of a packet from the sink node to the node 2 . The tests carried out have been similar to the previous ones.

\subsubsection{Average Jitter}

The average jitter has been measured based on the time obtained from the subtraction of the delay to two consecutive packet sending time. The average of these results is calculated giving the final average jitter measurement.

\section{Results And Discussion}

Figures 5 and 6 and Tables 3 and 4 presents the results corresponding to the tests previously explained. 
Table 3

Average results of 6LoWPAN performance in one hop test

\begin{tabular}{|c|c|c|c|c|}
\hline PERFORMANCE OF METRICS & DISTA & CE (m) & & \\
\hline Packet Loss (\%) & 10 & 20 & 30 & 40 \\
\hline LPL = 0 ms (No LPL) & 0,66 & 1,32 & 11,7 & 4,95 \\
\hline LPL = 1024 ms; Packet $120 \mathrm{~B}$ & 16,55 & 22,92 & 23,66 & 27,9 \\
\hline LPL = 1024 ms; Packet 1133 B & 66,45 & 56,91 & 73,26 & 75,39 \\
\hline RTT Length Time (s) & 10 & 20 & 30 & 40 \\
\hline $\mathrm{LPL}=0 \mathrm{~ms}$ (No LPL) & 0,67 & 0,66 & 0,82 & 0,79 \\
\hline LPL = 1024 ms; Packet $120 \mathrm{~B}$ & 0,52 & 0,52 & 0,52 & 0,52 \\
\hline LPL = 1024 ms; Packet 1133 B & 1,14 & 1,12 & 1,14 & 1,1 \\
\hline RTT Send Average Delay (s) & 10 & 20 & 30 & 40 \\
\hline $\mathrm{LPL}=0 \mathrm{~ms}$ (No LPL) & 1,01 & 1,01 & 1,13 & 1,05 \\
\hline LPL = 1024 ms; Packet 120 B & 1,2 & 1,3 & 1,31 & 1,38 \\
\hline LPL = 1024 ms; Packet 1133 B & 2,21 & 2,3 & 3,8 & 4,06 \\
\hline Packet Send Average Delay (s) & 10 & 20 & 30 & 40 \\
\hline $\mathrm{LPL}=0 \mathrm{~ms}$ (No LPL) & 1 & 1 & 1 & 1 \\
\hline LPL = 1024 ms; Packet 120 B & 1 & 1 & 1 & 1 \\
\hline LPL = 1024 ms; Packet 1133 B & 1,01 & 1 & 1,01 & 1,01 \\
\hline Jitter Packet Send (s) & 10 & 20 & 30 & 40 \\
\hline $\mathrm{LPL}=0 \mathrm{~ms}$ (No LPL) & 0 & 0,001 & 0,001 & 0,001 \\
\hline LPL = 1024 ms; Packet 120 B & 0,001 & 0,002 & 0,001 & 0,002 \\
\hline LPL = 1024 ms; Packet 1133 B & 0,005 & 0,005 & 0,005 & 0,005 \\
\hline
\end{tabular}


Table 4

Average results of 6LoWPAN performance in two hops test

\begin{tabular}{|c|c|c|c|c|}
\hline \multirow{2}{*}{$\begin{array}{l}\text { TEST } \\
\text { Packets Loss Rate (\%) }\end{array}$} & \multicolumn{2}{|c|}{ STATIC ROUTING } & \multicolumn{2}{|c|}{ RPL ROUTING } \\
\hline & Node 2 & Node 3 & Node 2 & Node 3 \\
\hline $\mathrm{LPL}=0 \mathrm{~ms}$ (No LPL) & 0 & 48,36 & 0,36 & 49,41 \\
\hline $\mathrm{LPL}=512 \mathrm{~ms}$ & 51,47 & 78,47 & 49,28 & 81,54 \\
\hline $\mathrm{LPL}=1024 \mathrm{~ms}$ & 60 & 79,66 & 56,76 & 82,77 \\
\hline RTT Length Time (s) & Node 2 & Node 3 & Node 2 & Node 3 \\
\hline LPL = $0 \mathrm{~ms}$ (No LPL) & 0,66 & 1,07 & 0,66 & 1,07 \\
\hline $\mathrm{LPL}=512 \mathrm{~ms}$ & 0,87 & 1,56 & 0,9 & 1,41 \\
\hline $\mathrm{LPL}=1024 \mathrm{~ms}$ & 1,13 & 2,12 & 1,12 & 2,07 \\
\hline RTT Send Average Delay (s) & Node 2 & Node 3 & Node 2 & Node 3 \\
\hline LPL = 0 ms (No LPL) & 1 & 1,93 & 1 & 1,98 \\
\hline $\mathrm{LPL}=512 \mathrm{~ms}$ & 2,07 & 4,81 & 1,98 & 5,33 \\
\hline $\mathrm{LPL}=1024 \mathrm{~ms}$ & 2,52 & 4,96 & 2,33 & 5,53 \\
\hline Packet Send Average Delay (s) & Node 2 & Node 3 & Node 2 & Node 3 \\
\hline $\mathrm{LPL}=0 \mathrm{~ms}$ (No LPL) & 1 & 1,002 & 1 & 1,003 \\
\hline $\mathrm{LPL}=512 \mathrm{~ms}$ & 1,003 & 1,005 & 1,003 & 1,006 \\
\hline $\mathrm{LPL}=1024 \mathrm{~ms}$ & 1,004 & 1,005 & 1,004 & 1,006 \\
\hline Jitter Packet Send (s) & Node 2 & Node 3 & Node 2 & Node 3 \\
\hline $\mathrm{LPL}=0 \mathrm{~ms}$ (No LPL) & 0 & 0,002 & 0 & 0,003 \\
\hline $\mathrm{LPL}=512 \mathrm{~ms}$ & 0,004 & 0,005 & 0,003 & 0,006 \\
\hline $\mathrm{LPL}=1024 \mathrm{~ms}$ & 0,004 & 0,005 & 0,004 & 0,005 \\
\hline
\end{tabular}

\subsection{Packet Losses}

Figure $5 \mathrm{~A}$ shows the results for the packet losses considering the distance differences, packet size and $L P L$ use. These results show that without $L P L$, the loss rate is lower than with $L P L$, ranging from $1-10 \%$. Using LPL with a $1024 \mathrm{~ms}$ sleep interval and 1133 Bytes packet size, the loss rate ranges from $68-72 \%$. The distances chosen do not exceed $40 \mathrm{~m}$. These experiment results show that the packet size has an impact on the loss rate, even being twice as much as the rate for 1133B packet size. It results interesting that increasing the distance does not show any impact in the results for this scenario and configuration. 
Figure 6A shows the packet losses for nodes 2 and 3, using static and dynamic routing. LPL with a configuration of 0,512 and $1024 \mathrm{~ms}$ has been applied, resulting the $1024 \mathrm{~ms}$ configuration, the best in terms of energy consumption. The Fig. 6A shows that the routing type does not affect the performance. Another interesting fact is that the node 2 does not lose any packet for the 0ms LPL-configuration, otherwise, the node 3 loses up to $50 \%$ more packets than the node 2 for the same scenario and configuration.

In the test with LPL the packet loss rate increases for the node 2 and 3 , but the difference between different LPL-configurations is not significant, even in the node 3 , where the differences are higher than in node 2.

\subsection{RTT Latency}

Tables 3 and 4 show the average RTT latencies. Figure 5B shows similar results for the different distances tested in the 1-hop scenario. The RTT with a lower packet size shows a shortest duration, due to the shortest processing time among the route. There is no significant difference for the RTT duration sending 120B between 0 and 1024 ms LPL-configuration. On the other hand, the RTT duration increases up to $50 \%$ for $1133 \mathrm{~B}$ sending with $1024 \mathrm{~ms}$ LPL-configuration. Finally, the best results are shown in the test sending 120B with $1024 \mathrm{~ms}$ LPL-configuration, showing also that the distances are not significant for the performance analysis. Figure 6B presents the RTT duration results for a 2-hops scenario, showing no significant difference in the results derived from the routing type. With $0 \mathrm{~ms}$ LPL-configuration the overall performance in terms of RTT duration is shorter than with the other configurations. The Fig. 6B also shows differences of $0.3 \mathrm{~s}$ for node 2 and $0.5 \mathrm{~s}$ for node 3 with a $512 \mathrm{~ms}$ LPL-configuration, however the RTT duration is even higher for a 1024 ms LPL-configuration. These test results show that node 3 has a higher RTT, almost being twice as much as the duration than node 2 shows, in all the 2-hop tests carried out, considering all the different configurations.

The application of a 0 ms LPL-configuration results in an increment in terms of energy consumption but it also results in an improvement of the RTT duration time. Thus, between a $512 \mathrm{~ms}$ and a $1024 \mathrm{~ms}$ LPLconfiguration, the RTT duration time differences are not significant, so it would be better to use a 1024 ms LPL-configuration in order to improve the energy consumption. Figure $5 \mathrm{C}$ presents the results in terms of RTT send average delay for 1-hop, showing a shorter delay for the $0 \mathrm{~ms}$ LPL-configuration configuration. Delay lightly increases with the distance as show the difference of $0.2 s$ between 10 and 40 $\mathrm{m}$ scenarios. This small difference does not affect the development of the tests. Figure $6 \mathrm{C}$ shows the results of RTT send average delay for 2-hops scenario, showing no significant differences between routing types. For a 0 ms LPL-configuration the RTT delay is generally shorter than for other LPLconfigurations. In this scenario, the difference between nodes is significant, reaching 2-3 seconds. For 512 and 1024 ms LPL-configurations there is no significant difference. Like in other scenarios, a 1024 ms LPL-configuration results in better energy consumption.

\subsection{Jitter}


Tables 3 and 4 show the packet sending delay and the jitter results for the 1- and 2-hops scenarios under different configurations. Figure 5D presents the packet sending delay for 1-hop scenarios, showing $1 \mathrm{~s}$ delay for all the distances considered, regardless the packet size. The delays detected have been very short 3-4 ms, which have been associated to the processing time among the route. There are no significant differences between 0 and 1024 ms LPL-configuration for 120B sending. Moreover, the distances do not present any significant influence in the jitter results.

Figure 6D presents the packet sending delay for 2-hops scenarios, confirming that routing type does not have any impact in the sending delay. For both routing types, $0 \mathrm{~ms}$ LPL-configuration shows a shorter delay than a 1024 ms LPL-configuration, but as collateral drawback shows higher energy consumption and $4 \mathrm{~ms}$ delay. Regarding to the jitter, Fig. 5E shows a higher jitter for 1-hop scenarios than for 2-hops scenarios. Configuration also plays a major role, showing a higher jitter sending $1133 \mathrm{~B}$ and using $1024 \mathrm{~ms}$ LPL-configuration. Changes in distances do not show any significant impact in jitter results. Figure $6 \mathrm{E}$ presents the jitter results for 2-hops scenarios, and it shows lightly differences, around $6 \mathrm{~ms}$ for all the cases analysed. For these tests, the shortest jitter is shown with a 0 ms LPL-configuration, whereas the other LPL-configurations do not present any significant difference. The difference between a 0 and $1024 \mathrm{~ms}$ LPL-configuration remains under $4 \mathrm{~ms}$, resulting much more suitable the $1024 \mathrm{~ms}$ LPLconfiguration in order to reduce the energy consumption. Again, the routing type does not impact the overall performance in terms of jitter.

\section{Conclusion}

Based on the 1-hop tests carried out, it seems to be better the use of $1024 \mathrm{~ms}$ as channel scanning time configuration (LPL-configuration) because the network performance does not drop and the energy consumption is reduced. It has been observed that the packet size is significant for this scenario, resulting the use of 1133B payload in longer delays and higher packet losses. Packet losses increase for 2-hops scenarios, reaching its maximum for node 3. The impact of the LPL-configuration is lightly significant in terms of packet losses, but more significant in terms of energy consumption. A $1024 \mathrm{~ms}$ LPL-configuration results in a good compromise between losses and energy consumption. Routing types do not present any significant difference for the different metrics analysed in the present paper. Packet sending delays are not significant between 1-and 2-hops scenarios, remaining under $5 \mathrm{~ms}$, thus, there is no significant impact in the network performance. Distances between nodes do not seem to be significant for the performance of network, at least, not for the considered scenarios and configurations. It is highly recommended to use $1024 \mathrm{~ms}$ LPL-configuration, not only for 1-hop scenarios, but also for 2-hops scenarios in order to obtain an overall improvement in terms of energy consumption.

Finally, the TelosB platform is a system that allows its use for evaluation of data transmission. Although it is not a robust system, its use for monitoring flash floods is possible by implementing sensors such as rain gauges, given its easy integration. Currently the literature does not evidence works that apply the TelosB platform and the 6LoWPAN method for flash flood monitoring systems. 


\section{List Of Abbreviations}

6LowPAN: IPV6 Low Power Wireless Personal Area Networks

BAN: Body Area Networks

BLIP: Berkeley Low-Power IP stack

EWS: Early Warning System

ICMPV6: Internet Control Message Protocol for the Internet Protocol Version 6

IETF: Internet Engineering Task Force

IoT: Internet of Things

LPL: Low Power Listening

NEMO: Networking mobility

RPL: Routing Protocol for Low-Power and Lossy Networks

RTT: Round Trip Times

WPAN: Wireless Personal Area Networks

WSN: Wireless Sensor Networks

\section{Declarations}

Availability of data and materials: The authors declare that all the data and materials in this manuscript are available.

Competing Interest: There is no competing interest.

Funding: As the paper is supported by the $1^{\text {st }}$ author by the Universidad de la costa< Barranquilla, Colombia.

\section{References}

1. R. James, The Internet of things: a study in hype, reality, disruption, and Growth. Raymond James US Research, Technology \& Communications, Industry Report. 2014

2. D. Evans, The Internet of Things How the Next Evolution of the Internet Is Changing Everything. Cisco Internet Business Solutions Group (IBSG). 2011; 1-11 
3. I. Lee, K. Lee, The Internet of Things (IoT): Applications, investments, and challenges for enterprises. Bus. Horiz. 58(4), 431-440 (2015). http://dx.doi.org/10.1016/j.bushor.2015.03.008

4. G. Piñeres-Espitia, A. Mejía-Neira, Technological platforms applied the climatic monitoring. Prospectiva 11(2), 78-87 (2013). DOl:http://dx.doi.org/10.15665/rp.v11i2.42

5. A. Foerster, A. Udugama, C. Görg, K. Kuladinithi, A. Timm-Giel, A. Cama-Pinto. A novel data dissemination model for organic data flows. Lecture Notes of the Institute for Computer Sciences, Social-Informatics and Telecommunications Engineering, LNICST. 2015; 158:239-252 p. http://dx.doi.org/10.1007/978-3-319-26925-2_18

6. F. Estevez, P. Glosekoetter, J. González, DARAL: A Dynamic and Adaptive Routing Algorithm for Wireless Sensor Networks. Sensors. 16(7), 960 (2016). doi:10.3390/s16070960

7. M. Bouaziz, A. Rachedi, A survey on mobility management protocols in Wireless Sensor Networks based on 6LoWPAN technology. Comput. Commun. 74, 3-15 (2016)

8. J. Granjal, E. Monteiro, J.S. Silva, Security for the internet of things: a survey of existing protocols and open research issues. IEEE Communications Surveys \& Tutorials 17(3), 1294-1312 (2015)

9. J. Vasseur, A. Dunkels. Interconnecting Smart Objects with IP: The Next Internet. United States. Morgan Kaufmann Publisher/Elsevier; 2010. 231 p

10. A. Zanella, N. Bui, A. Castellani, L. Vangelista, M. Zorzi, Internet of Things for Smart Cities. IEEE Internet of Things Journal 1(1), 22-32 (2014). doi:10.1109/JIOT.2014.2306328

11. T.N. Quynh, N. Le Manh, K.N. Nguyen. Multipath RPL protocols for greenhouse environment monitoring system based on Internet of Things. 2015 12th International Conference on Electrical Engineering/Electronics, Computer, Telecommunications and Information Technology (ECTI-CON). 2015; 1-6 p. doi: 10.1109/ECTICon.2015.7207135

12. A. Cenedese, A. Zanella, L. Vangelista, M. Zorzi Padova Smart City: An urban Internet of Things experimentation. Proceeding of IEEE International Symposium on a World of Wireless, Mobile and Multimedia Networks, 2014. 2014; 1-6. doi: 10.1109/WoWMoM.2014.6918931

13. A. Cama-Pinto, G. Piñeres-Espitia, Z. Comas-González, J. Zapata-Vélez, F. Gómez-Mula, Design of a monitoring network of meteorological variables related to tornadoes in Barranquilla-Colombia and its metropolitan area. Ingeniare. Revista chilena de ingeniería 24(4), 585-598 (2017)

14. El Heraldo. Proyecto universitario sobre arroyos será financiado por Colciencias. 2013. https://www.elheraldo.co/local/proyecto-universitario-sobre-arroyos-sera-financiado-por-colciencias103883. Accessed 06 November 2017

15. C. Walravens, W. Dehaene. Design of a low-energy data processing architecture for WSN nodes. Design, Automation \& Test in Europe Conference \& Exhibition. 2012; 570-573. doi: 10.1109/DATE.2012.6176534

16. O. Hahm, E. Baccelli, H. Petersen, N. Tsiftes, Operating systems for low-end devices in the internet of things: a survey. IEEE Internet of Things Journal 3(5), 720-734 (2015)

17. M. Khan, A. Lodhi, A. Rehman, A. Khan, F. Hussain, Sink-to-Sink Coordination Framework Using RPL: Routing Protocol for Low Power and Lossy Networks. Journal of Sensors 11(4), 2002-2019 (2016). 
doi:10.1155/2016/2635429

18. T. Dinh, Y. Kim, T. Gu, A.V. Vasilakos, An adaptive low-power listening protocol for wireless sensor networks in noisy environments. IEEE systems journal 12(3), 2162-2173 (2017)

19. V. Chandrasekar, H. Chen, B. Philips, "DFW urban radar network observations of floods, tornadoes and hail storms," 2018 IEEE Radar Conference (RadarConf18), Oklahoma City, OK, 2018, pp. 07650770. doi: 10.1109/RADAR.2018.8378656

20. 20 Lemon, L. R., Donaldson Jr, R. J., Burgess, D. W., \& Brown, R. A. (1977). Doppler radar application to severe thunderstorm study and potential real-time warning. Bulletin of the American Meteorological Society, 58(11), 1187-1193. https://doi.org/10.1175/15200477(1977)058<1187:DRATST>2.0.C0;2

21. C. 21 Corral, M. Berenguer, D. Sempere-Torres, L. Poletti, F. Silvestro, N. Rebora, Comparison of two early warning systems for regional flash flood hazard forecasting. J. Hydrol. (2019). https://doi.org/10.1016/j.jhydrol.2019.03.026

22. A. 22 Schimmel, J. Hübl, Automatic detection of debris flows and debris floods based on a combination of infrasound and seismic signals. Landslides 13(5), 1181-1196 (2016)

23. N. 23 Ya'acob, N. Tajudin, A.M. Azize, Rainfall-landslide early warning system (RLEWS) using TRMM precipitation estimates. Indonesian Journal of Electrical Engineering and Computer Science 13(3), 1259-1266 (2019). DOI:10.11591/ijeecs.v13.i3.pp1259-1266

24. S. 24 Segoni, L. Piciullo, S.L. Gariano, A review of the recent literature on rainfall thresholds for landslide occurrence. Landslides 15(8), 1483-1501 (2018)

25. A. 25 Schimmel, J. Hübl, Automatic detection of debris flows and debris floods based on a combination of infrasound and seismic signals. Landslides 13(5), 1181-1196 (2016)

26. M. 26 Azam, S. Kim, H., \& S.J. Maeng, Development of flood alert application in Mushim stream watershed Korea. International journal of disaster risk reduction 21, 11-26 (2017)

27. C. 27 Cecioni, G. Bellotti, A. Romano, A. Abdolali, P. Sammarco, L. Franco, Tsunami early warning system based on real-time measurements of hydro-acoustic waves. Procedia Eng. 70, 311-320 (2014)

28. B.S.B. 28 Dewantara, F. Ardilla (2018). Early Warning and loT-based Reporting System for Mobile Trash Bin Robot Application. In 2018 International Electronics Symposium on Knowledge Creation and Intelligent Computing (IES-KCIC) (pp. 341-348). IEEE

29. N.-A. 29 Maspo, A.N. Harun, M. Goto, M.N.M. Nawi, N.A. Haron, Development of internet of thing (lot) technology for flood prediction and early warning system (EWS). International Journal of Innovative Technology and Exploring Engineering 8(4S), 219-228 (2019)

30. R.H. 30 Randhawa, R. Mahmood, T. Ahmad (2018, December). AquaEye: A Low Cost Flood Early Warning System for Developing Countries. In 2018 International Conference on Frontiers of Information Technology (FIT) (pp. 345-349). IEEE

31. 31 Intrieri, E., Gigli, G., Gracchi, T., Nocentini, M., Lombardi, L., Mugnai, F.,... \& Fornaciai, A. (2018). Application of an ultra-wide band sensor-free wireless network for ground monitoring. Engineering 
Geology, 238, 1-14

32. 32 A. Cama-Pinto, G. Piñeres-Espitia, R. Zamora-Musa, M. Acosta-Coll, J. Caicedo-Ortiz, J. SepulvedaOjeda. Design of a wireless sensor network for monitoring of flash floods in the city of Barranquilla Colombia. Ingeniare. Revista chilena de ingeniería. 2016; 24(4):581-599.

http://dx.doi.org/10.4067/S0718-33052016000400005

33. 33. J. Arrieta, Y. Fernández. Estimación De Los Caudales Del Arroyo La Segunda Brigada II Para Diferentes Períodos De Retorno Aplicando La Herramienta Computacional Epa-Swmm. 2015. http://hdl.handle.net/11323/490. Accessed November 29, 2017

34. 34. A. Raad, D. Villa. Diseño y desarrollo de una aplicación móvil para dispositivos android para un sistema de alerta temprana de los arroyos de la ciudad de Barranquilla. 2014. http://hdl.handle.net/11323/238. Accessed November 29, 2017

35. 35. A. Chatap, S. Sirsikar. Review on various routing protocols for heterogeneous wireless sensor network. In I-SMAC (IOT in Social, Mobile, Analytics and Cloud)(I-SMAC), 2017 International Conference on. 2017; 440-444

36. 36. J. He, X. Huang. Increased interoperability: Evolution of 6LoWPAN-based web application. 4th IEEE International Conference on Broadband Network and Multimedia Technology (IC-BNMT), Shenzhen. 2011; 507-510. doi: 10.1109/ICBNMT.2011.6155986

37. 37. D.W. Courtney, P. Thulasiraman (2016, April). Implementation of secure 6LoWPAN communications for tactical wireless sensor networks. In 2016 IEEE Conference on Computer Communications Workshops (INFOCOM WKSHPS) (pp. 704-709). IEEE

38. 38. Y. Ch, K. Hou, H. Zhou, H. Shi, X. Liu, X. Diao, H. Ding, J. Li, C. Vaulx 6LoWPAN Stacks: A Survey. 7th International Conference on Wireless Communications, Networking and Mobile Computing (WiCOM), Wuhan, 2011; 1-4. doi: 10.1109/wicom.2011.6040344

39. 39. Z. Suryady, M. Shaharil, K. Bakar, R. Khoshdelniat. G.R. Sinniah, U. Sarwar. Performance evaluation of 6LoWPAN-based precision agriculture. International Conference on Information Networking (ICOIN), 2011; 171-176 p. doi: 10.1109/ICOIN.2011.5723173

40. R. Chai, Y. Zhao, Q. Chen, T. Dong, W. Zhou. Group mobility in 6LoWPAN-based WSN. International Conference on Wireless Communications and Signal Processing (WCSP). 2010; 1-5. doi: 10.1109/WCSP.2010.5633536

41. V. Michopoulos, L. Guan, G. Oikonomou, I. Phillips. A comparative study of congestion control algorithms in IPv6 Wireless Sensor Networks. International Conference on Distributed Computing in Sensor Systems and Workshops (DCOSS). 2011; 1-6. doi: 10.1109/DCOSS.2011.5982218

42. S. Raza, S. Duquennoy, T. Chung, D. Yazar, T. Voigt, U. Roedig. Securing communication in 6LoWPAN with compressed Ipsec. International Conference on Distributed Computing in Sensor Systems and Workshops (DCOSS). 2011; 1-8. doi: 10.1109/DCOSS.2011.5982177

43. M. Bouaziz, A. Rachedi, A survey on mobility management protocols in Wireless Sensor Networks based on 6LoWPAN technology. Comput. Commun. 74, 3-15 (2016) 
44. S.R. Moosavi, T.N. Gia, E. Nigussie, A.M. Rahmani, S. Virtanen, H. Tenhunen, J. Isoaho, End-to-end security scheme for mobility enabled healthcare Internet of Things. Future Generation Computer Systems 64, 108-124 (2016)

45. S. Takizawa, N. Komuro, S. Sakata. Routing control scheme prolonging network lifetime in a 6LoWPAN WSN with Power-supplied and battery-powered nodes. IEEE Consumer Communications and Networking Conference (CCNC). 2012; 285-289. doi: 10.1109/CCNC.2012.6181103

46. A. Efendi, S. Oh, A. Negara, D. Choi. Battery-Less 6LoWPAN-Based Wireless Home Automation by Use of Energy Harvesting. Int. J. Distrib. Sens. Netw. 2013; 9(7) doi:10.1155/2013/924576

47. Montoya F, Gómez J, Cama-Pinto A, Zapata-Sierra A, Martínez F, De La Cruz J, Manzano-Agugliaro F. A monitoring system for intensive agriculture based on mesh networks and the android system. Computers and Electronics in Agriculture 2013; 99: 14-20. <http://dx.doi.org/10.1016/j.compag.2013.08.028>.

48. A. Cama-Pinto, F. Montoya, J. Gómez, J. De La Cruz, F. Manzano-Agugliaro, Integration of communication technologies in sensor networks to monitor the Amazon environment. J. Clean. Prod. 59, 32-42 (2013). http://dx.doi.org/10.1016/j.jclepro.2013.06.041

49. P.A. Neves, J.J. Rodrigues, M. Chen, A.V. Vasilakos, A multi-channel architecture for IPv6-enabled wireless sensor and actuator networks featuring PnP support. Journal of Network and Computer Applications 37, 12-24 (2014)

50. C. Pham, Communication performances of IEEE 802.15.4 wireless sensor motes for data-intensive applications: A comparison of WaspMote, Arduino MEGA, TelosB, MicaZ and iMote2 for image surveillance. Journal of Network and Computer Applications. 46, 48-59 (2014). http://dx.doi.org/10.1016/j.jnca.2014.08.002

51. M. Hefeida, T. Canli, A. Khokhar. CL-MAC:, A Cross-Layer MAC protocol for heterogeneous Wireless Sensor Networks. Ad Hoc Netw. 11(1), 213-225 (2013). http://dx.doi.org/10.1016/j.adhoc.2012.05.005

52. A. Nahas, S. Duquennoy, V. lyer, T. Voigt. Low-Power Listening Goes Multi-channel. IEEE International Conference on Distributed Computing in Sensor Systems (DCOSS). 2014; 2-9. doi: 10.1109/DCOSS.2014.33

53. O. Gaddour, A. Koubâa, RPL in a nutshell: A survey. Comput. Netw. 56(14), 3163-3178 (2012). http://dx.doi.org/10.1016/j.comnet.2012.06.016

54. S. Sankar Bhunia, S. Kumar Das, S. Roy, N. Mukherjee, An Approach to Manage Mobility of Sensor Nodes in Sensor-Grid Infrastructure. Procedia Technol. 6, 754-762 (2012). http://dx.doi.org/10.1016/j.protcy.2012.10.091

55. J. Santos, J.J. Rodrigues, B.M. Silva, J. Casal, K. Saleem, V. Denisov, An loT-based mobile gateway for intelligent personal assistants on mobile health environments. Journal of Network and Computer Applications 71, 194-204 (2016)

56. N. Hoque, M.H. Bhuyan, R.C. Baishya, D.K. Bhattacharyya, J.K. Kalita, Network attacks: Taxonomy, tools and systems. Journal of Network and Computer Applications 40, 307-324 (2014) 
57. F. Montoya, J. Gomez, F. Manzano-Agugliaro, A. Cama, A. García-Cruz, J. De La Cruz, 6LoWSoft: A software suite for the design of outdoor environmental measurements. Journal of Food, Agriculture and Environment. 11(3-4), 2584-2586 (2013)

58. A. Kamilaris, V. Trifa, A. Pitsillides. HomeWeb: An application framework for Web-based smart homes. 18th International Conference on Telecommunications (ICT), 2011; 134-139. doi: 10.1109/CTS.2011.5898905

59. N. Baccour, A. Koubâa, H. Youssef, M. Alves, Reliable link quality estimation in low-power wireless networks and its impact on tree-routing. Ad Hoc Netw. 27, 1-25 (2015). http://dx.doi.org/10.1016/j.adhoc.2014.11.011

60. A. Cama-Pinto, G. Piñeres-Espitia, J. Caicedo-Ortiz, E. Ramírez-Cerpa, F. Betancur-Agudelo, GómezMula, Received strength signal intensity performance analysis in wireless sensor network using Arduino platform and XBee wireless modules. Int. J. Distrib. Sens. Netw. 13(7), 1-10 (2017). https://doi.org/10.1177/1550147717722691

\section{Figures}

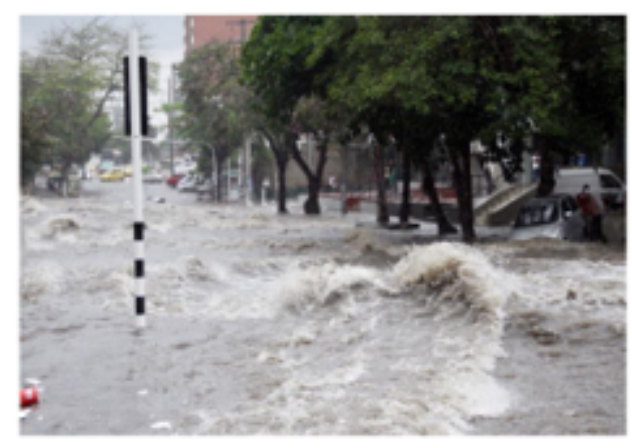

A

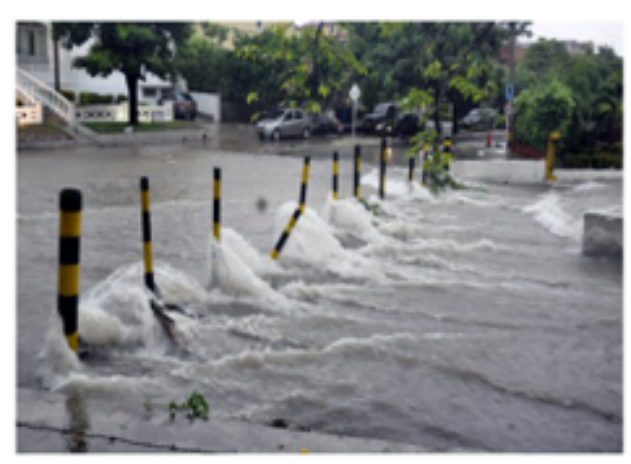

C

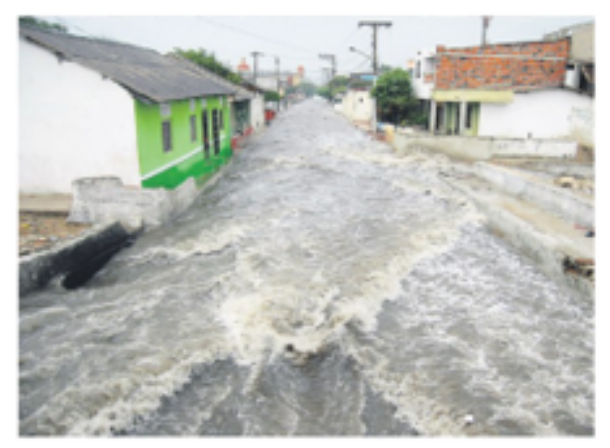

B

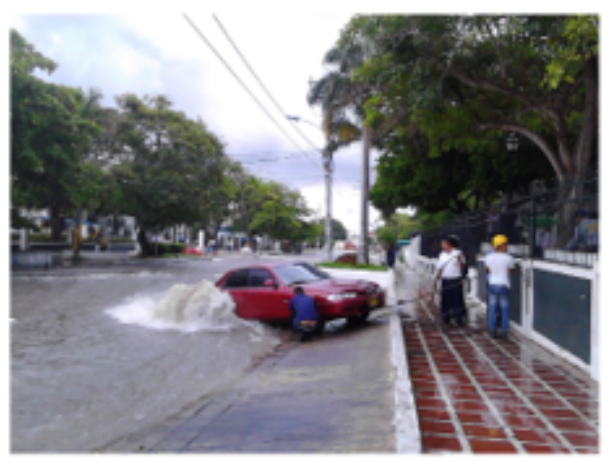

D

\section{Figure 1}

A-B. Flash foods Barranquilla City. B-C. Flash food in "The Brigade" zone. 


\section{Network Layer}

\section{RPL}

\section{LOWPAN - IPV6}

\section{Data Link Layer}

\section{IEEE 802.15.4 MAC PROTOCOL}

\section{Figure 2}

RPL-6LoWPAN network stack

Physical Layer

$$
\begin{gathered}
\text { IEEE } 802.15 .4 \\
\text { PHYSICAL LAYER } \\
800-900 \mathrm{MHz}
\end{gathered}
$$

IEEE 802.15.4 PHYSICAL LAYER $2,4 \mathrm{GHz}$ 


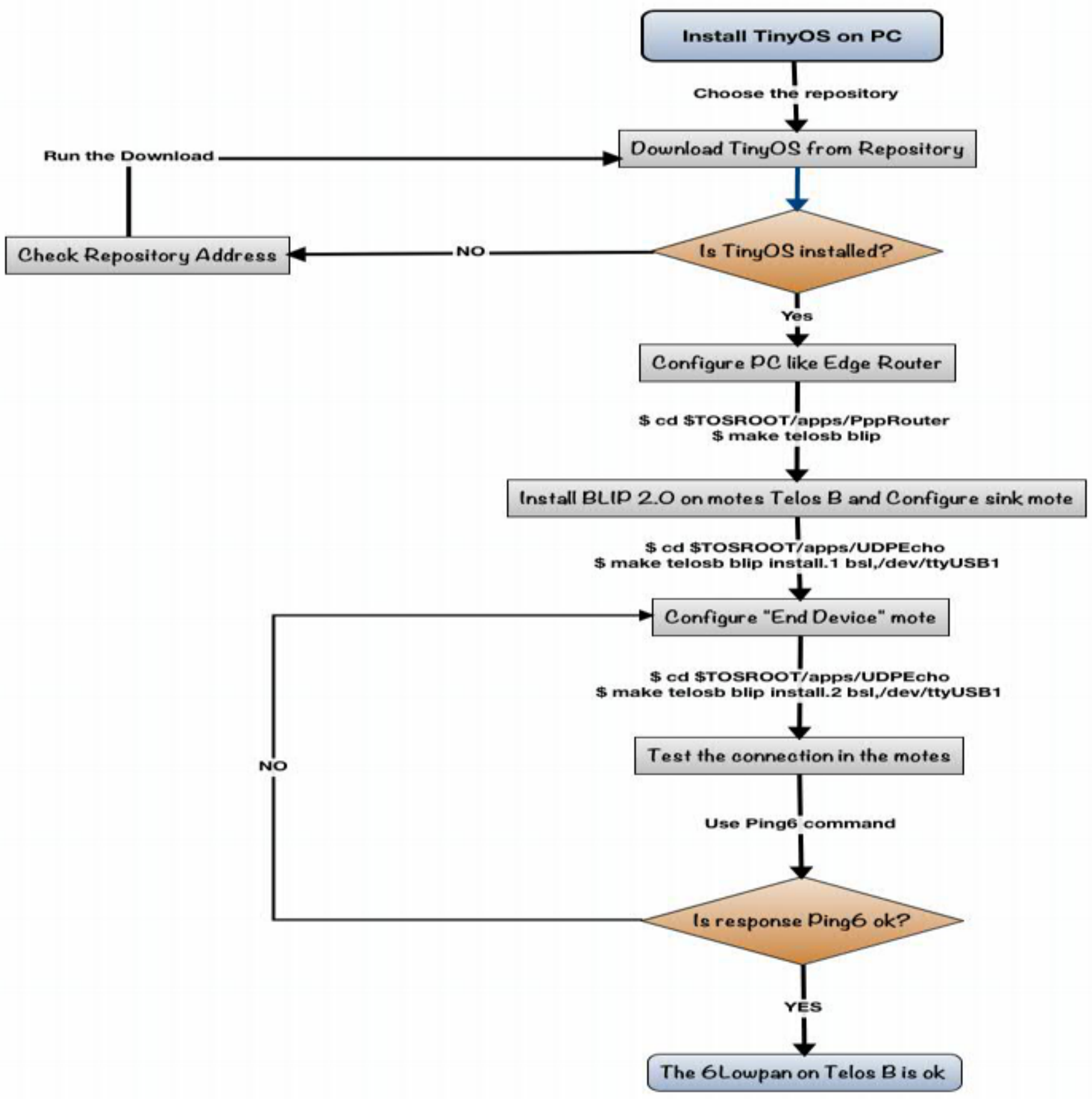

Figure 3

Steps by configuration the TelosB platform. 

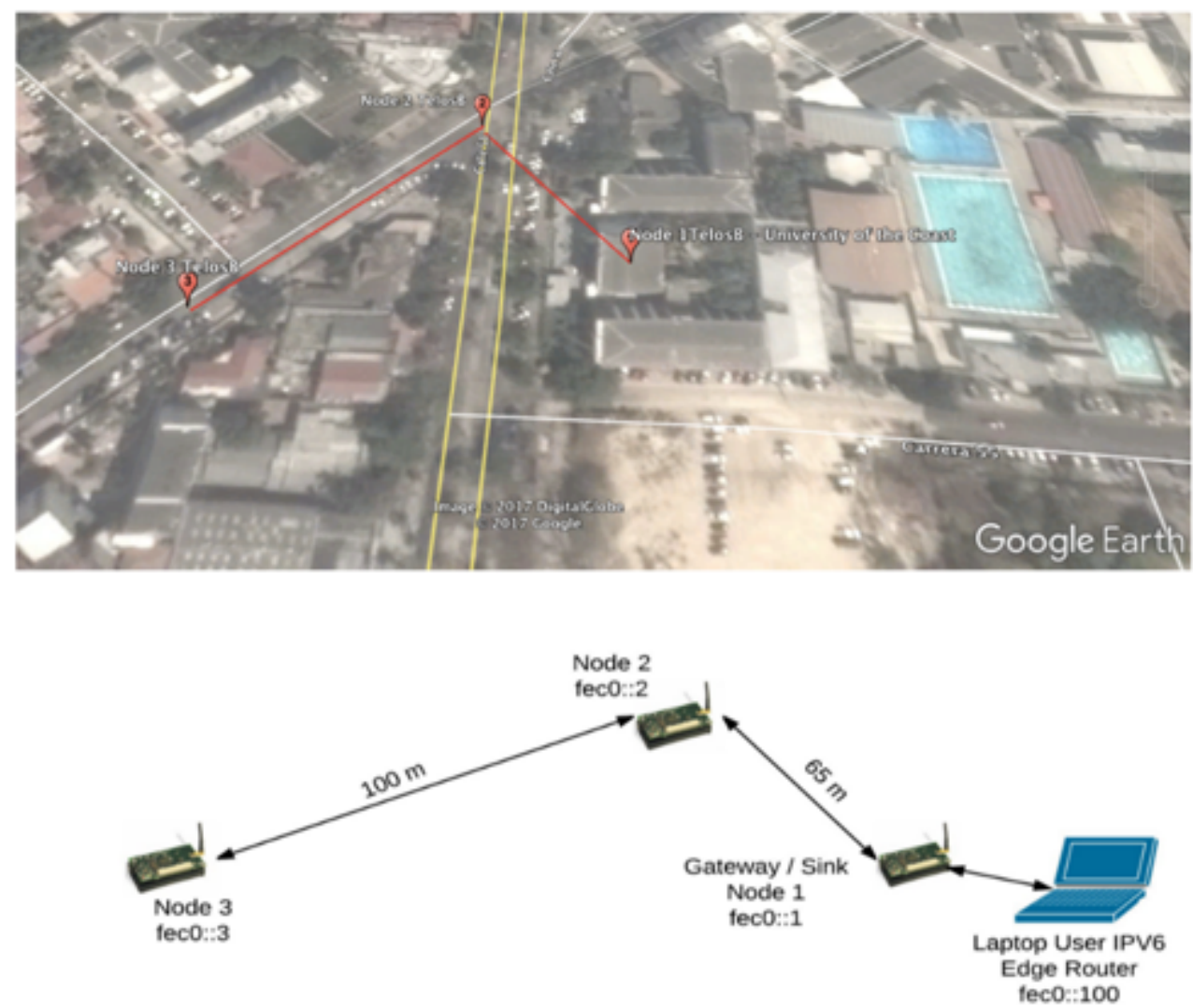

Figure 4

Snapshot of the scenario tested 

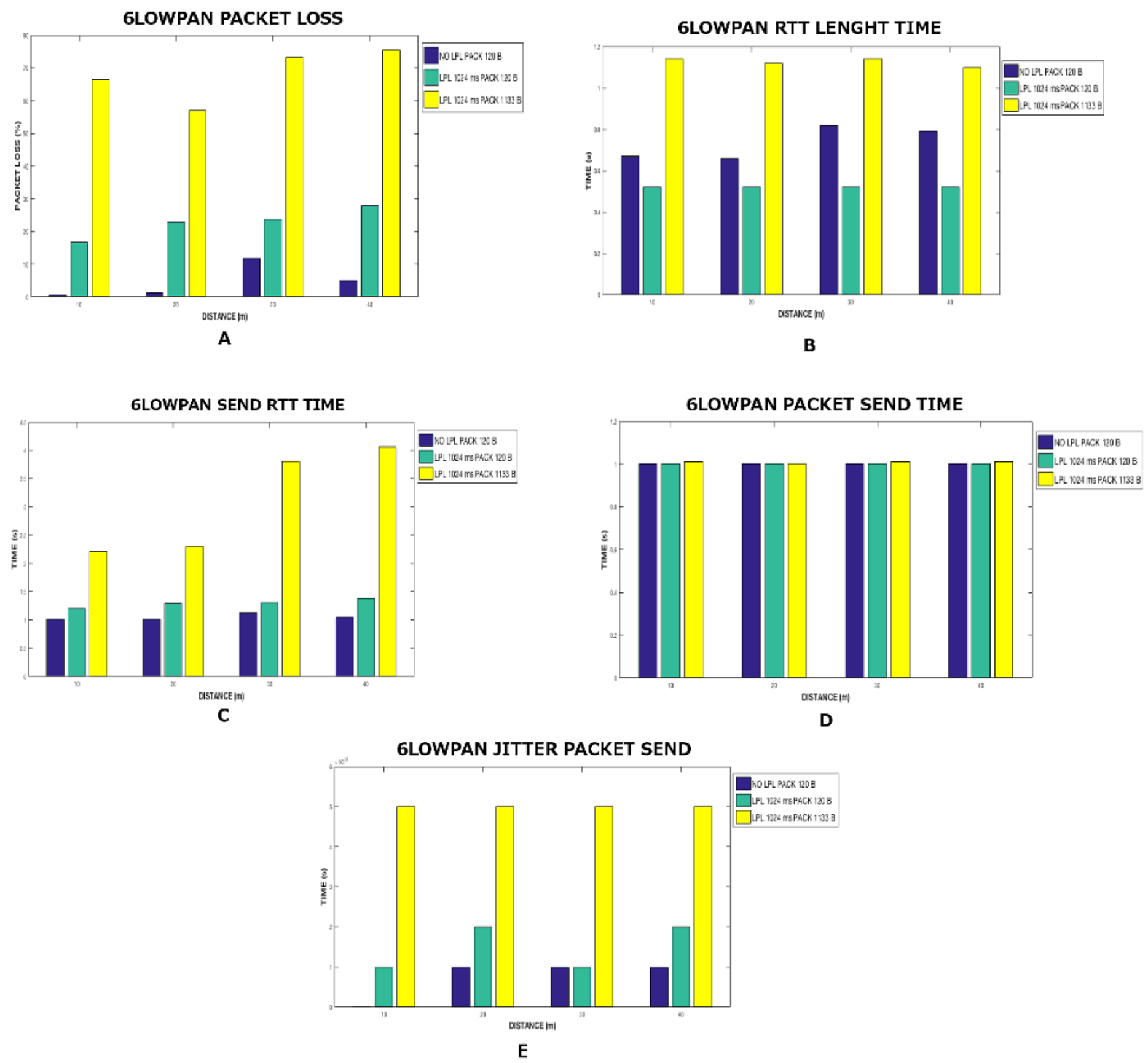

Figure 5

Results obtained in the 1-hop tests 

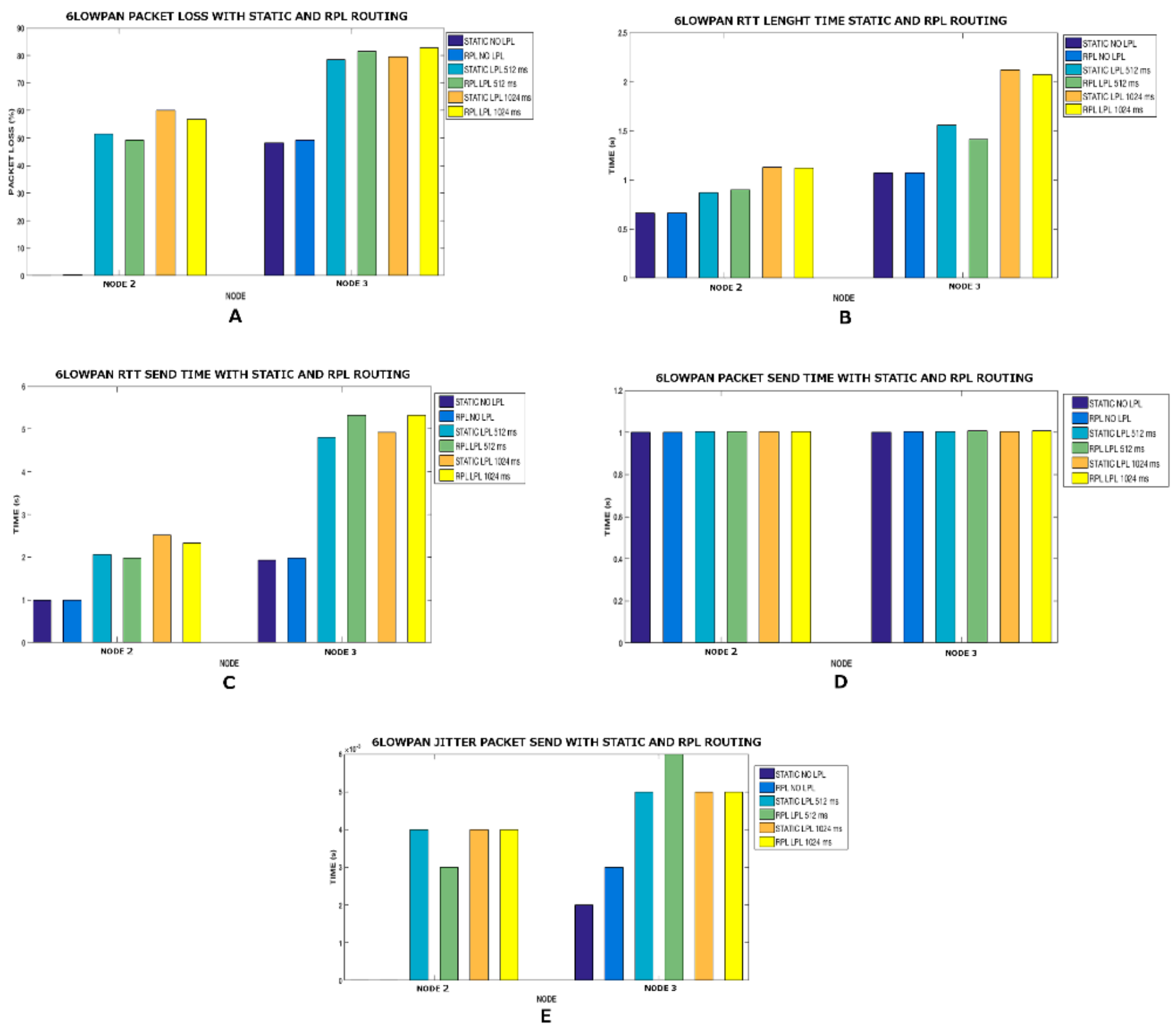

Figure 6

Results obtained in the 2-hops tests 